PAPERS

\title{
Terminal care: evaluation of effects on surviving family of care before and after bereavement
}

\author{
JEAN CAMERON \\ M.A. \\ COLIN MURRAY PARKES \\ M.D., D.P.H., F.R.C.Psych. \\ Palliative Care Unit, Royal Victoria Hospital, Montreal, Canada and \\ Department of Psychiatry, London Hospital Medical College, London E1 2AD
}

\begin{abstract}
Summary
To evaluate the effects on the family of a comprehensive programme of terminal cancer care, 20 close relatives of patients who had died in a Palliative Care Unit (PCU) were compared with a matched group of 20 relatives of patients who had died of cancer in other wards of the same teaching hospital.

Interviewed by telephone 1 year and 2 weeks after bereavement, relatives of $P C U$ patients report significantly fewer psychological symptoms and less lasting grief and anger than relatives of patients who had died elsewhere.

Factors thought to have contributed to good outcomes were successful relief of pain, awareness by relatives of the coming death of the patient and support given to relatives after bereavement. Two case examples illustrate these findings.
\end{abstract}

KEY WORDS: bereavement, terminal care, thanatology, hospice.

\section{Introduction}

Although the principles of 'hospice' care for patients with incurable cancer had been widely accepted before any systematic research had been published confirming its value, there have been several scientific studies in recent years which have borne out clinical impressions that these approaches benefit the patient in a variety of ways (Hinton, 1979; Lack and Buckingham, 1978).

Hospices also aim to help the patient's family by providing counselling and support before and after bereavement and evaluations of this aspect of care have seldom been reported. Exceptions are the series of studies of the effects on surviving spouses of inpatient care, home care and bereavement care at St Christopher's Hospice in London. The first of these studies was carried out before the introduction of a bereavement service and showed that surviving spouses of patients who had died in the hospice after a stay of more than one week suffered less anxiety and associated symptoms than a control group of spouses of comparable patients who had died in other hospitals (Parkes, 1979a). By contrast, the introduction of a counselling nurse to provide support to families nursing a cancer patient at home made no measurable impact on anxiety levels in spouses, probably because it resulted in the patient remaining at home until a later stage of the illness (the length of in-patient stay was halved) and placed an added burden on the family (Parkes, 1980).

Although the first study had revealed no significant differences between hospice and non-hospice spouses after the patient's death, the introduction of a bereavement service for relatives who were thought to be at special risk proved successful. A random allocation study demonstrated that, after the service had become established, spouses who received bereavement counselling had significantly fewer somatic indicators of tension and anxiety, consumed less psychotropic drugs, alcohol and tobacco and had a better overall outcome than non-counselled controls (Parkes, 1979b).

The Palliative Care Unit at the Royal Victoria Hospital in Montreal has adopted many of the principles of 'hospice' care, but it differs from St Christopher's Hospice in important respects. It is situated within a large teaching hospital rather than free-standing, it provides consultation to patients and staff in all parts of the hospital and its home care staff and volunteers provide direct service to patients and families at home whereas the St Christopher's Hospice Domiciliary Care Service provides only consulting services to support the primary care team. In 
addition, there are all the cultural and organizational differences between health care in London, England and Montreal, Canada. It follows that systematic evaluation of the effects of the Montreal service on families can be expected to add to our understanding of this new kind of service.

\section{Method of investigation}

The aim of the study was to evaluate the effect of the service provided by the Palliative Care Unit (PCU) upon the surviving relatives of patients who had died thereby comparing them with a matched group of relatives of patients who had died in other wards of the same hospital.

\section{Experimental treatment}

As close relatives of PCU patients, the subjects in the PCU group were exposed to the comprehensive service programmes provided on this unit to both the dying and their families. These included facilitating expression of anticipatory grief, providing optimal care and symptom control for the dying, fostering open communication between the patient and loved ones, and encouraging the survivor to be present at the time of death.

When death occurred the relatives were encouraged to be present and to view the body. A staff member, present to support the family as required, touched the body unobtrusively and if the family concurred, a commemorative prayer was read by all present, family and staff.

The bereaved were subsequently contacted one to two weeks after the death by a PCU nurse. An informal counselling programme averaging one or two visits and two to three telephone contacts over 6 months followed. The person involved in the support programme was the staff nurse from the PCU who had had the closest relationship with the family during their relative's admission. The support offered varied from reassurance and active listening to referral to a specialist for more in depth assistance as required. While both types of intervention were utilized, contacts were made primarily over the telephone rather than through personal visits. All but 4 persons in the PCU group had more than one contact during the year following bereavement. None of the controls received this service or any similar one, although one control subject received support from a religious representative, as did 5 PCU subjects.

\section{Evaluation}

Kin of patients who had died from cancer in the Royal Victoria Hospital were identified from the hospital records and interviewed on the telephone by one of us (J.C.) one year and two weeks after the्ष patient's death. Systematic questions were askeq covering the demographic characteristics of the respondents, the amount of warning and conseor quences of the death and a 'health-adjustment inventory' of 32 questions covering psychologicas aspects of bereavement and mental health was completed. These questions were derived from previ零 ous studies of the reaction to bereavement.

After interviewing was complete the protocols were examined to identify two matched groups fo $\vec{P}$ further analysis. Matching criteria were sex, relation $\vec{\exists}$ ship to deceased and, as far as possible, living arrangements before and since bereavement (i.eo whether the respondent lived alone, with adul children or with young children).

\section{Results}

Attempts were made to contact 68 people for the study. Of these 4 had moved away, 2 did not reply despite 6 calls, 3 refused to answer questions. This left 59 who were interviewed for the project. Satsfactory matching was obtained from 20 matched pairs (1 1 e women and 6 men). These included 8 widows, 5y widowers, 4 daughters, 2 parents and one sister. AIT subjects were thought to have been the person mast likely to have been affected by the loss.

The mean age of the PCU group was 50.4 yeâs: and of the comparison group 56.9 years.

One year and two weeks after bereavement the control group reported a mean of 14 symptoms each compared with 4.5 in the PCU group $\left(P=<0.002 \frac{8}{D}\right.$ Wilcoxon's sum of ranks test). It is clear from this that the relatives of patients who had died in the Palliative Care Unit had adjusted better to their bereavement than relatives of patients who had dief in other wards.

A clearer idea of the meaning of these differences? can be obtained from Table 1 which shows the replies to the 18 questions (out of 32) which distinguished $B$. the two groups. The significance of these differences was tested using Fisher's test.

It will be seen from these figures that three-o quarters of the control group felt that their health had deteriorated after bereavement and had not yet begun to improve. Fifty per cent were taking sleeping. pills and almost as many were taking tranquillizerso By contrast $40 \%$ of the PCU group reported deterior N ation in health, one-fifth were taking sedatives and N one of them $(5 \%)$ was taking tranquillizers.

The control group were more likely to exhibit signs? of continuing psychological stress and persisting grie but the most striking finding was a marked tendencye for them to express feelings of persisting irritability and anger. This was evident in $85 \%$ (17) of the controls and only one (5\%) of the PCU cases. It was. 
TABLE 1. Incidence of 18 symptoms and features of grief in 20 Palliative Care Unit (PCU) relatives and 20 control unit relatives

\begin{tabular}{|c|c|c|}
\hline & PCU & Controls \\
\hline \multicolumn{3}{|l|}{ 1. Stress symptoms } \\
\hline Has not recovered lost appetite & 1 & 5 \\
\hline Sleep worse since bereavement & $13^{*}$ & $19 *$ \\
\hline Using sleeping pills since bereavement & 4 & 10 \\
\hline Using tranquillizers since bereavement & $1^{* *}$ & $9 * *$ \\
\hline $\begin{array}{l}\text { Health, deteriorated at bereavement and not } \\
\text { improved }\end{array}$ & 8 & 15 \\
\hline \multicolumn{3}{|l|}{ 2. Psychological stress reactions } \\
\hline $\begin{array}{l}\text { Is hyperactive } \\
\text { Is unable to carry out everyday }\end{array}$ & 2 & 5 \\
\hline responsibilities & 0 & 3 \\
\hline Experiences panic attacks & 0 & 1 \\
\hline Death wish and suicidal ideation & 2 & 4 \\
\hline Is socially withdrawn & 3 & 7 \\
\hline Tearfulness & 8 & 11 \\
\hline \multicolumn{3}{|l|}{ 3. Persisting features of grief } \\
\hline Pining and seeking & 5 & 10 \\
\hline Sense of presence of dead person & 5 & 9 \\
\hline Irritability and anger & $1^{*}$ & $17^{*}$ \\
\hline Is hostile towards others & $0^{* *}$ & $10^{* *}$ \\
\hline Guilt & 2 & 7 \\
\hline Feels uncomfortable with reminders & 1 & 4 \\
\hline $\begin{array}{l}\text { Believes to have developed symptoms of the } \\
\text { dead person }\end{array}$ & 0 & 2 \\
\hline
\end{tabular}

${ }^{*} P<0.05, \quad * * P<0.01$.

also reflected in the measure of hostility towards others' which was reported by half the controls but none of the PCU cases.

Other questions which were not included in the health adjustment inventory also distinguished the two groups. In response to an open-ended question regarding 'the most difficult thing you had to bear . during the year', half the control subjects referred to distressing memories of the dead person's unrelieved pain. The remaining half and all of the PCU subjects referred to loneliness and other consequences of bereavement $\left(\chi^{2}=13.3, P<0.005\right)$. Indeed, the PCU subjects repeatedly expressed appreciation of the care that had been given and the contribution which this had made to their peace of mind.

Sixteen of the PCU group and 7 controls knew at least 4 days in advance that the patient was about to die. After excluding those who were said to have suffered unrelieved pain it was clear that relatives who had been aware of the outcome had a better overall outcome (mean score 3.0 ) than those who had not been aware (mean score $12 \cdot 3$ ), regardless of their group (PCU or control). Although too small a group for statistical analysis, it is also worth noting that four members of the PCU group who received no bereavement support had similar outcome scores to those of the control group.

There was evidence of an association between age and outcome with those in the older age groups having a poorer outcome than those in the younger. In view of the discrepancy in mean age between the PCU group and the controls it was necessary to examine this difference more closely. It will be clear from Fig. 1 that only a small part of the differences between groups could be explained by this discrepancy.

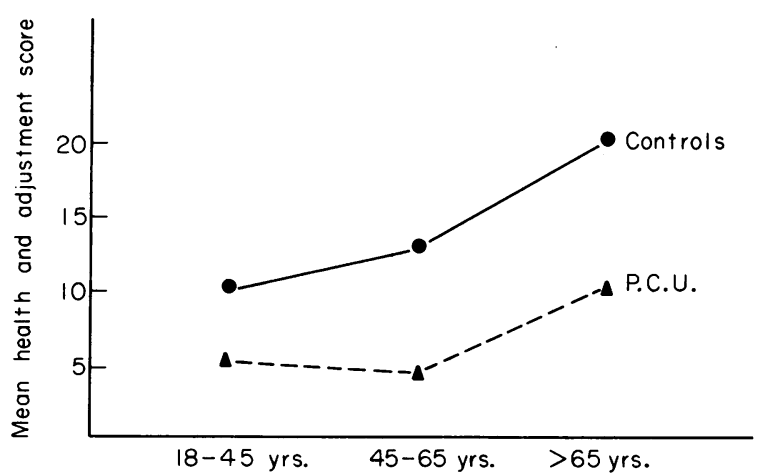

Fig. 1. Mean health and adjustment in control and Palliative Care Unit (PCU) relatives according to age.

\section{Discussion}

It would seem unlikely that the large differences in outcome between PCU relatives and controls can be accounted for by selective factors although we cannot overlook the fact that patients were not assigned at random to the two types of care. Thus there does seem to be some evidence that younger families were more likely to be referred to the Palliative Care Unit than to other wards but this would only explain a small part of the difference in outcome between the two groups.

Age as a factor in bereavement outcome has been considered in several studies. In general it is not surprising that older people, whose health is likely to be worse than that of young people at the best of times, show more signs of ill health after bereavement. What is more surprising is the finding in our study that measures of persisting 'grief' were higher in the older age group. This finding conflicts with Parkes' study of the consultations which London widows had with their general practitioners, in which there was a sevenfold increase in consumption of sedatives and a fourfold increase in psychological symptoms among widows under the age of 65 during the first 6 months of bereavement, but very little increase in older widows (Parkes, 1964).

It is not possible to know for sure which aspects of the total package of care explains the outcome among PCU families. Our data indicate that two aspects are 
particularly important - the provision of adequate pain relief for the patient and advance knowledge by the family that death is imminent. There is also some evidence that bereavement support can be helpful.

Satisfactory relief of distressing symptoms has been demonstrated in several evaluations of hospice care (Hinton, 1979; Parkes, 1979a). This is achieved by meticulous attention to the individual needs of each patient, continuous monitoring of drug responses and frequent use of narcotic drugs in 4hourly dosages in order to keep the patient free of pain. Used in this way, analgesic dosage can often be kept to a minimum allowing the patient to remain alert and mobile. By contrast, doctors working in other settings are often reluctant to use narcotic drugs at all, and even then they prescribe them to be given 'as required' so that the patient is in severe pain before relief is attempted, by which time anaesthetic doses may be needed to get the situation under control [see Twycross's paper (1972) for a full discussion of these issues].

Our study indicates that relatives of patients who have suffered severe, unrelieved pain before death, are left with intense feelings of anger which disturb their sleep and impair the process of grieving.

\section{Case report}

'I am so angry that I still want to kill that doctor-he just didn't come. I can't forget, complained one widow from the control group. This lady described herself as tormented by memories. She had frequently recurring nightmares during which she saw her husband's pain-wracked body and she shouted and cried aloud, and pleaded with him not to go away and leave her.

Neighbours in the apartment building complained to the landlord about the noise and disturbance. He threatened to evict the widow and she became afraid to sleep. Her married son explained the situation to the landlord who vas then more sympathetic and patient. He agreed to postpone any action for a month in the hope that Mrs M. might settle down and adjust. However, after two months had elapsed the complaints had become so numerous that he said he had no alternative but to ask her to move.

The son had visited daily and spent many hours trying to help his mother during the first months of her bereavement. He described how he had tried to reason with her and help her to understand that his father was now dead and freed from pain. He said that she had refused to listen and had become increasingly more demanding and unreasonable. She complained of numerous physical symptoms but would not trust herself to a doctor's care. She also refused psychiatric help.
Relatives of PCU patients were more likely than controls to have known that death was imminent a? least four days before that event took place. It may seem surprising that two-thirds of the control group denied this degree of awareness when most of them must have known that the patient had incurable cancer. Our study indicates that communication between hospital staff and family members in thep control group was very poor and that this gave rise to much fear and anger about what was happening an ${ }^{\circ}$ what to expect. One widower said that the doctor was never available to talk to him or answer his telephone calls. He never realized that his wife was about to die Even when interviewed he was still unaware of the cause of death. He described how, during her lass week-end at home, he and his wife used to sit outside in the sunshine to regain her strength and plan theifo future together. When she died the shock was so greabo that he found himself unable to work or to care adequately for his 6-year-old daughter. Angry, dis $\omega$ tressed and suicidally inclined, he was preoccupief with fears and thoughts of his wife: 'I think of her alt the time and often feel that she is still at home with me.' His daughter had stopped laughing and playing을 had lost weight and was doing badly at school.

The combination of shock, anger and persisting illusions of the continual presence of the dead persono is typical of the reaction to sudden, untimely berearee ments and is likely to be followed by lasting dist and loss of function (Parkes and Weiss, 1982). Thio 'Unanticipated Death Syndrome' may be hard to treat, but is often preventable by providing accurate information about the situation well in advance of $\frac{0}{\mathrm{D}}$ death accompanied by the emotional support which enables the family to take it in and prepare them? selves for what is to come. In many cases it is possible for the patient to be similarly informed and sup ported so that everyone is on the same "wavelength? and mutual sharing is possible.

\section{Case report}

Mr B. arrived at the Palliative Care Unit complain $\frac{\hat{\circ}}{3}$ ing of severe pain. He was obviously exhausted and showing signs of depression. He was accompanied by his wife who appeared tired and anxious. She was, in turn, apologetic and angry as she tried to explain the absence of their 17-year-old son. Later in the day sheू became very upset as she told the doctor about the particularly close relationship which had existed between father and son until the last few weeks. Now, $\omega$ she said, Michael had become sullen, morose and unhelpful. He no longer spent any time with hifo father and was out of the house most days from morning until late at night. The day before Mr B's admission Michael told his mother that he was? abandoning his plans to go to University and was 
about to leave home and find a job in another city. Mrs B. could offer no explanation for the changed attitude and said that although her husband had said little, she knew he was deeply hurt by their son's behaviour.

Within a few days of admission, Mr B's pain was successfully controlled and both he and his wife seemed more relaxed. A week went by and then Michael appeared at the hospital and paid a very brief visit to his father. On the way out he stopped at the nursing station and expressed surprise at his father's pain-free state.

The next day Michael returned for a longer visit. He again spoke to the staff and asked many questions about his father's condition. He continued to visit and one day he confided to one of the nurses some of the fears and concerns which had threatened his relationship with both his parents. He said that he had been unable to bear the sight of his father's suffering; the few times when he was not in intolerable pain he had seemed drugged and incoherent. Seeing no end to it, Michael had stayed away from the house. There had never been any discussion about the outcome of Mr B's illness, but Michael had begun to realize that he could not recover. He was alarmed by the thought that he might have to abandon plans for his future career in order to stay home and look after his mother whom he described as helpless, clinging and dependent. He had decided to escape before he could be trapped into that situation.

During the weeks that followed Michael visited frequently. When he found his father relaxed, comfortable and alert they had long talks together. Sometimes he stayed to chat when his mother arrived for the afternoon. All three began to talk quite openly with each other and with the staff. They were aware that Mr B. was unlikely to live for more than a few weeks. Michael was surprised to find that, after a few days of tearfulness, his mother was able to discuss the future quite calmly. She talked of her plans to resume a part-time job and on more than one occasion he heard her reassuring his father tiat plans for his University career would not have to be changed. Michael was surprised at her strength and resilience. His father seemed to relax although he grew weaker.

One day Mr B. recalled plans that they had made to visit his brother in Vancouver some months earlier. When the time came for the trip he had felt tired and, in the expectation of improved health later, they had postponed the trip. Mr B. regretted this now and said that if he had been made aware of the likely outcome of his disease he would have made the effort to go. Now it was too late. Mrs B. telephoned the brother the next day and explained the circumstances. He and his wife were able to take an early vacation. They visited Montreal and were able to pay several visits to the hospital. The brothers enjoyed their reunion even though Mr B. was, by then, feeling weak and tired.

Mrs B. and Michael were able to stay in the PCU during the last night of Mr B's life and were with him when he died. When they left to go home Michael was heard to say how thankful he was that he would be able to be at home to help his mother over the next few months before he left for the University.

We suspect that medical and nursing staff thought that the control families were aware of the facts of the case. Parkes' study (1970) of London widows showed that although most had been warned of the seriousness of their spouse's illness, few had understood what they had been told and their estimates of prognosis were often grossly inaccurate. It takes time to break bad news and to give the support that is necessary if it is to be digested and to give rise to appropriate 'worry work'. However, this time is well spent and should become recognized as an important responsibility for every doctor and nurse who is caring for dying patients and their families.

\section{Conclusions}

If a PCU provides support to the family before bereavement, it is logical to continue this afterwards. Other studies (Raphael, 1977; Parkes, 1979b) have confirmed the impressions of this study that such counselling can reduce the incidence of lasting maladjustment.

Attitudes to bereavement support can be judged from some of the comments made by PCU family members: 'You cannot know how much it helped to be able to talk about all that happened, to people who understood and who had been there sharing it all with you.'-'When you are desperately lonely, it is good to be able to talk to people who really care.'- 'Those calls and the feeling that I could call when things were very bad helped me more than anything. I really miss them now.'- 'At a time like that, you find that most people are embarrassed and don't really want to listen. It was such a comfort to know I could pour it all out to someone who understood.'-'I shall always feel close to those people who were so kind, but I don't seem to need their support quite as much now.'

Not that everyone felt the need for support. There were several people who felt well supported by their families and others who expected to cope without help. But the overall consensus was that bereavement counselling was helpful and none had felt harmed by it.

\section{Acknowledgments}

Thanks are due to Margaret Keily and Barbara Brings for helping with the analysis of the data, to the staff of the Royal Victoria 
Hospital for providing information and, most particularly, to the many bereaved people who were willing to share their opinions and their feelings about a time of great distress.

\section{References}

Hinton, J. (1979) Comparison of places and policies for terminal care. Lancet, i, 29.

LACK, S.A. \& Buckingham, R.W. (1978) The First American Hospice. Hospice Inc., 765 Prospect St., New Haven.

PARKES, C.M. (1964) The effects of bereavement on physical and mental health. A study of the case records of widows. British Medical Journal, 2, 274.

PARKES, C.M. (1970) The first year of bereavement: A longitudinal study of the reactions of London widows to the death of theiro husbands. Psychiatry, 33, 444.

PARKES, C.M. (1979a) Terminal care: evaluation of in-patient $c$ service at St Christopher's Hospice. Postgraduate Medical Journal $\overrightarrow{\overrightarrow{\vec{n}}}$ 55, 517.

PARKES, C.M. (1979b) Evaluation of a bereavement service. In: The Dying Human (Ed. by De Vries, A. \& Carmi, A.) p. 389.ర Turtledove, Ramat Gan, Israel.

PARKES, C.M. (1980) Terminal care: evaluation of an advisory domiciliary service at St. Christopher's Hopice. Postgraduatę Medical Journal, 56, 685.

PARKES, C.M. \& WEISS, R.S. (1982) Recovery from Bereavement, Basic Books, New York.

RAPHAEL, B. (1977) Preventive intervention with the recentlybereaved. Archives of General Psychiatry, 34, 1450.

TWYCROSS, R.G. (1972) Principles and practice of the relief of paino in terminal cancer. Update, July.

(Accepted 11 August 1982) 